\title{
Editorial da edição RENOTE Vol 19 Nº 2 (2021-2)
}

Liane Margarida Rockenbach Tarouco

A edição atual da RENOTE traz artigos abordando as temáticas inerentes à novas tecnologias na educação. Foram submetidos 152 artigos e taxa de aceitação foi de 34,6\%.

Os artigos publicados na RENOTE continuam tendo aumento na quantidade de citações. O valor do H-index atual é de 42, medido usando o programa Harsing's Publish or Perish ${ }^{1}$ (versão 8 de 2021), que contempla toda a produção desde 2003 quando a RENOTE começou a ser publicada. Pelo Google acadêmico o índice de citação H5 (que corresponde aos útimos 5 anos) é 12.

A nuvem de palavras abaixo ilustra os principais temas abordados, a partir dos títulos.

Figura 1: Nuvem de palavras com as principais palavras usadas nos títulos

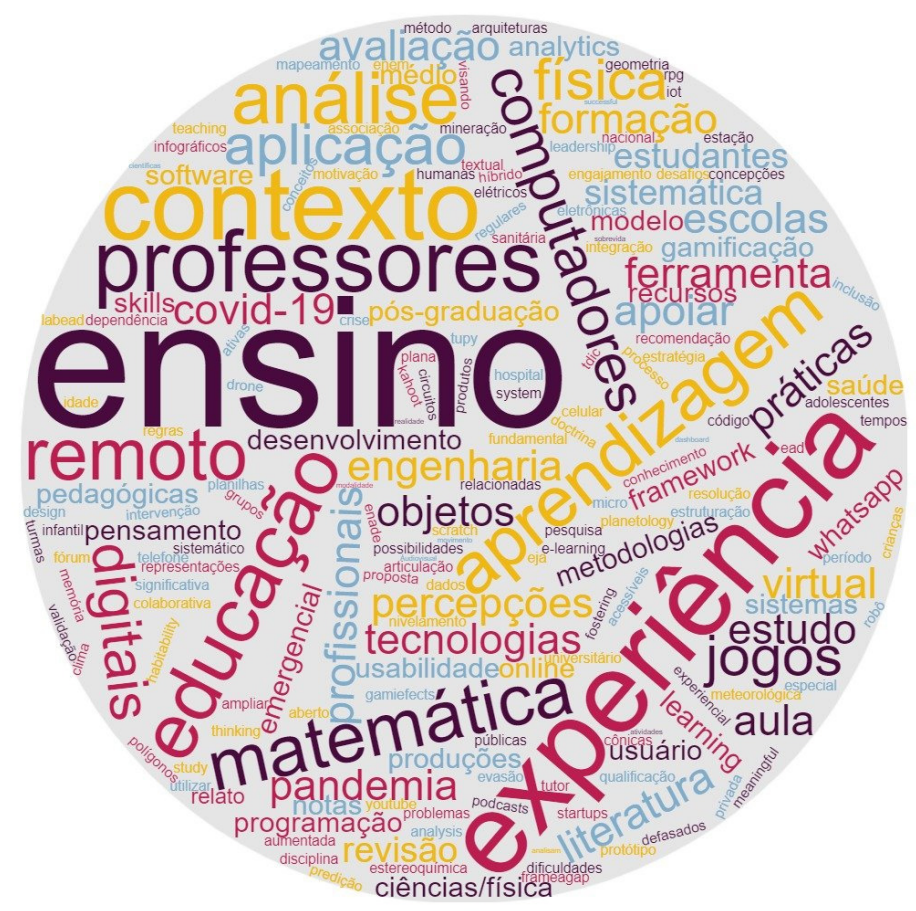

A temática predominante continua sendo o ensino e a aprendizagem em um ambiente permeado pela tecnologia. A tabela seguinte mostra os tópicos mais frequentes indicados pelos autores.

Tabela 1: Tópicos mais frequentes selecionados pelos autores dos artigos

\begin{tabular}{|l|c|}
\hline Tópico & $\begin{array}{c}\text { Frequência de } \\
\text { artigos }\end{array}$ \\
\hline Ensino e aprendizagem mediados por computador & 20 \\
\hline Ambientes virtuais de aprendizagem & 11 \\
\hline Teorias educacionais aplicadas à TIC & 11 \\
\hline
\end{tabular}

\footnotetext{
${ }^{1}$ Harzing, A.W. (2007) Publish or Perish, available from https://harzing.com/resources/publish-or-perish
} 


\begin{tabular}{|l|l|} 
Aprendizagem Colaborativa Apoiada por Computador & 9 \\
\hline Educação a distância & 8 \\
\hline Jogos digitais aplicados ao ensino/aprendizagem & 8 \\
\hline Mineração de dados educacionais & 8 \\
\hline Projeto e desenvolvimento de objetos educacionais & 8 \\
\hline $\begin{array}{l}\text { Inclusão digital } \\
\text { Informática na Educação Especial }\end{array}$ & 5 \\
\hline Software educacional & 5 \\
\hline Tecnologias móveis e mobile learning na educação & 5 \\
\hline $\begin{array}{l}\text { Plataformas abertas, código aberto, software livre e seus } \\
\text { impactos, usos e metodologias em processos de ensino- } \\
\text { aprendizagem }\end{array}$ & \\
\hline Laboratórios digitais & 4 \\
\hline $\begin{array}{l}\text { Ambientes Inteligentes para Aprendizagems } \\
\text { Inteligência Artificial na Educação }\end{array}$ & 3 \\
\hline Realidade virtual e aumentada na Educação & 2 \\
\hline Vídeo educacional & 2 \\
\hline
\end{tabular}

Os artigos submetidos nesta edição da RENOTE 2021-2 foram provenientes da maioria dos estados do Brasil com duas submissões com autores da Europa (Portugal e Holanda). O mapa abaixo ilustra a proveniência das submissões. Os estados em cor mais escura (RS, SP e PE) foram os que tiveram maior quantidade de artigos submetidos.

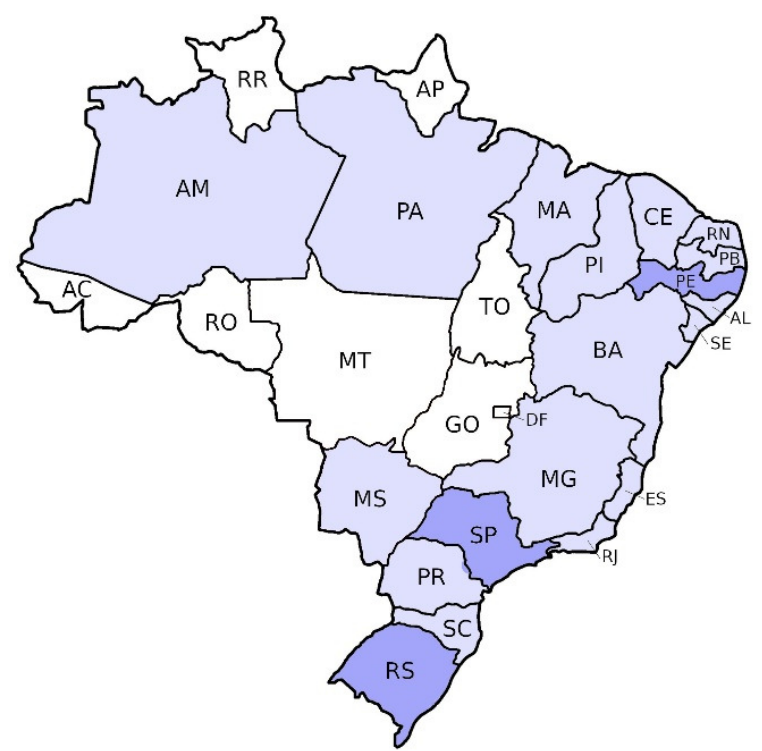

O processo de revisão contou com a colaboração de 69 avaliadores também provenientes de diversos estados do Brasil bem como de Portugal. 